\title{
Essential elements of radical pair magnetosensitivity in Drosophila
}

\author{
Adam A Bradlaugh1, Giorgio Fedele², Anna L Munro', Celia Napier \\ Hansen², Charalambos P. Kyriacou², Alex R. Jones ${ }^{3}$, Ezio Rosato ${ }^{2 *}$, and \\ Richard A. Baines ${ }^{1 *}$
}

${ }^{1}$ Division of Neuroscience and Experimental Psychology, School of Biological Sciences, Faculty of Biology, Medicine and Health, University of Manchester, Manchester Academic Health Science Centre, Manchester, M13 9PL, UK. '2Department of Genetics, University of Leicester, LE1 7RH, UK. ${ }^{3}$ National Physical Laboratory, Teddington, Middlesex, TW11 OLW, UK.

${ }^{*}$ Corresponding authors

Email: Richard.Baines@manchester.ac.uk; er6@leicester.ac.uk

Conflict of interest statement. The authors declare no competing financial interests.

Acknowledgements. We thank Sanjai Patel (Manchester Fly Facility) who carried out injections for transgenic stock generation, and Matt Hemsley and John Hares for the cloning and production of CRY-CT mutants and flies. ARJ thanks Ines Camacho and Mike Shaw for useful feedback on the manuscript. This work was supported by funding from the Leverhulme Trust to RAB, and ARJ (RPG-2017-113) and to RAB from BBSRC (BB/V005987/1). Work on this project benefited from the Manchester Fly Facility, established through funds from the University and the Wellcome Trust (087742/Z/08/Z). ARJ thanks the National Measurement System of the Department for Business, Energy and Industrial Strategy for funding. GF, $\mathrm{CNH}$, ER and CPK acknowledge funding from the Electromagnetic Field Biological Research Trust. 
bioRxiv preprint doi: https:/doi.org/10.1101/2021.10.29.466426; this version posted November 1, 2021. The copyright holder for this preprint (which was not certified by peer review) is the author/funder, who has granted bioRxiv a license to display the preprint in perpetuity. It is made available under aCC-BY 4.0 International license.

CRY-independent magnetosensitivity

\section{Summary:}

Many animals use the Earth's magnetic field (geoMF) for navigation ${ }^{1}$. The favored mechanism for magnetosensitivity involves a blue-light $(\mathrm{BL})$ activated electron transfer reaction between flavin adenine dinucleotide (FAD) and a chain of tryptophan (Trp) residues within the photoreceptor protein, CRYPTOCHROME (CRY). The spin-state of the resultant radical pair $(\mathrm{RP})$ and hence the concentration of $\mathrm{CRY}$ in its active state is influenced by the geoMF². The canonical CRY-centric radical pair mechanism (RPM) does not, however, explain many physiological and behavioural observations ${ }^{2-8}$. Here, using electrophysiology and behavioural analyses, we assay magnetic field (MF) responses at single neuron and organismal level. We show that the 52 C-terminal (CT) amino acids of CRY, which are missing the FAD binding domain and the Trp chain, are sufficient to facilitate magnetoreception. We also show that increasing intracellular FAD potentiates both BL-induced and MF-dependent effects on the activity mediated by the CT. Additionally, high levels of FAD alone are sufficient to cause BL neuronal sensitivity and, remarkably, potentiation of this response in the co-presence of a MF. These unexpected results reveal the essential components of a primary magnetoreceptor in flies, providing strong evidence that non-canonical (i.e., non-CRY-dependent) RPs can elicit MF responses in cells.

\section{Introduction}

The ability of species to navigate considerable distances has long intrigued the biological community ${ }^{1}$. One of several environmental cues to support these migrations is the geoMF. The identity of the primary magnetoreceptor(s), the mechanism(s) that underlies its reported light dependence and how the magnetic signal is transduced remain unknown ${ }^{9,10}$. A favoured model posits a light-induced electron transfer reaction whereby RPs are formed, the spinstates of which are sensitive to MFs as small as the geoMF $(\sim 50 \mu \mathrm{T})^{2}$. This so-called RPM canonically requires the flavoprotein $\mathrm{CRY}$, which is best known for its role as a circadian $\mathrm{BL}$ photoreceptor in flies and as a light-insensitive transcriptional regulator in the circadian clock of mammals ${ }^{2,9}$.

Absorption of BL by CRY-bound FAD initiates an electron transfer cascade along a conserved chain of Trp residues ${ }^{2,11-13}$. In Drosophila this forms a spin-correlated RP comprising the photoreduced FAD (FAD $\left.{ }^{-}\right)$and the terminal oxidised $\operatorname{Trp}\left(\operatorname{TrpH}^{\circ+}\right)^{14}$. The spin-state of the RP is initially polarised as a singlet ( $\mathrm{S}$, anti-parallel spins), which then rapidly oscillates between $S$ and the triplet spin states ( $T$, parallel spins). Transiently (i.e., before the system relaxes to equilibrium), this inter-conversion can be sensitive to MF, which in turn can lead to 
bioRxiv preprint doi: https://doi.org/10.1101/2021.10.29.466426; this version posted November 1, 2021. The copyright holder for this preprint (which was not certified by peer review) is the author/funder, who has granted bioRxiv a license to display the preprint in perpetuity. It is made available under aCC-BY 4.0 International license.

CRY-independent magnetosensitivity

downstream modifications in the biological activity of CRY, via conformational change ${ }^{2}$. In its activated state, the CRY C-terminal 'tail' of $\sim 20$ residues (CTT) becomes exposed, allowing interactions with signalling partners including PDZ-domain containing proteins ${ }^{15-21}$.

Although there is ample evidence consistent with CRY being both necessary and sufficient for light-dependent magnetosensitivity, there are a number of studies that support exceptions to this mechanism ${ }^{2-8}$. In one of the most striking, Fedele and colleagues used a circadian behavioural assay in Drosophila to show that CRY-dependent light and magnetosensitivity could be rescued in CRY-null adult flies via expression of the 52 CT residues of CRY fused to GFP (GFP-CT) for stability ${ }^{3}$. Furthermore, CRY $\Delta$, resulting from the deletion of the CTT of CRY, appeared largely insensitive to a MF, although BL sensitivity was maintained ${ }^{3,4}$.

The Drosophila CRY-CT lacks both a FAD-binding pocket and the Trp residues (W394, W342, W397, W420) necessary for the canonical RPM ${ }^{2,22-24}$. Moreover, mutating these Trp residues, including W420F and W342F, at best attenuates, but does not abolish the magnetic functionality of $C R Y^{3,4,25,26}$. These results are inconsistent with current understanding of the RPM and question the identity of the magnetically-sensitive RP in the receptor. Proposed alternatives to a RP between $\mathrm{FAD}^{\mathrm{o}-}$ and $\mathrm{TrpH}^{\mathrm{o}+}$ include the formation of a RP between $\mathrm{FAD} \mathrm{D}^{-}$ $/ \mathrm{FADH}^{\circ}$ and $\mathrm{O}_{2}{ }^{-0}$ or another (unknown, $\mathrm{Z}^{\circ}$ ) radical. It is a matter of some contention whether these 'unconventional' RPs contribute to magnetoreception or even represent a primary sensor ${ }^{10,27-29}$.

Here we report the expression of a new transgene encoding Luc-CT (CRY-CT fused to luciferase), which lacks a FAD-binding pocket and the Trp residues and thus, is unable to support light-induced intramolecular electron transfer. Nevertheless, Luc-CT is sufficient to generate changes in $\mathrm{BL}$ and MF-dependent phenotypes in a whole organism circadian behavioural assay and in the electrophysiological activity of a model neuron, the larval aCC motoneuron. We show that the MF-responsiveness of Luc-CT is potentiated by increasing the intracellular concentration of free $F A D$, to the point where high levels of this flavin alone are capable, in the absence of Luc-CT, to support a MF response. Finally, we confirm by mutational analysis that the integrity of the CTT of CRY correlates with its ability to facilitate sensitivity to a MF. Overall, our results suggest that trafficking of the RP is more important than the specific nature of the RP itself and that the ability to detect MFs by RPs is likely to be a widespread property of cells. It is possible that this logic has been optimised through evolution of molecules such as CRY that function both as a sensor and as a transducer. 
bioRxiv preprint doi: https://doi.org/10.1101/2021.10.29.466426; this version posted November 1, 2021. The copyright holder for this preprint (which was not certified by peer review) is the author/funder, who has granted bioRxiv a license to display the preprint in perpetuity. It is made available under aCC-BY 4.0 International license.

CRY-independent magnetosensitivity

\section{Results and Discussion}

\section{CRY-CT is sufficient to support magnetosensitivity consistent with a RPM.}

To validate our electrophysiological assay we expressed full-length Drosophila CRY (DmCry) in the aCC motoneuron; this supported a BL-induced increase in action potential (AP) firing by 1.7-fold and by 2.4-fold, in the co-presence of a MF (BL+MF,100 mT, Fig.1Aii,iii-B, $p=0.005$, see also Extended Data Fig.1)4. Expression of CRY-CT (fused to GFP) in a cry-null background supports a MF-induced shortening of circadian period ${ }^{3}$. To eliminate the possibility that GFP might, like CRY, support intramolecular light-induced electron-transfer, we fused CRY-CT to Luciferase (Luc-CT) and maintained the flies in the absence of luciferin substrate. $\mathrm{BL}$ lengthened the free-running period of tim-GAL4 > UAS-Luc-CT; $c r y^{02} / \mathrm{cry}^{02}$ flies compared to those in constant darkness (DD) $(23.75 \vee 24.50 \mathrm{~h}$ respectively, $\mathrm{p}=0.019)$ revealing the $\mathrm{BL}$ light-sensitivity of CRY-CT. As with the GFP-CT construct ${ }^{17}$, Luc-CT exposure to a MF (300 $\mu \mathrm{T}, 3 \mathrm{~Hz}$ ) was sufficient to shorten the free-running circadian period in the MF exposed but not the sham group (Fig.1Ci, pre-exposure/post-exposure $x$ sham/MF interaction $F_{1,377}=7.6$, $p=0.006$, Extended Data Fig.2A-D). Remarkably, expression of Luc-CT in aCC supported a $\mathrm{BL}$-induced increase in AP firing (1.4-fold), which was increased further in the co-presence of a MF (Fig.1Cii, 2-fold, $\mathrm{p}=0.002$ ).

\section{CRY CT is not a RP partner}

Although CRY-bound FAD may be dispensable, it is possible that free FAD in proximity could interact by forming a RP with the sole Trp in the CRY CT. This alternative mechanism may explain why mutations of single Trp residues that constitute the Trp-tetrad are not significantly detrimental to CRY dependent magnetoreception ${ }^{3,4,25,30}$. The Trp residue in CRY-CT has not been implicated in the canonical RPM. However, theoretically it is capable of generating a RP with free FAD reminiscent of the interaction between Flavin mononucleotide and the surface Trp of lysozyme ${ }^{31}$. Thus, we substituted this residue (W536) for a less redox-active phenylalanine.

Expression of Luc-CT $\mathrm{W}_{\mathrm{W}(536) \mathrm{F}}$ was sufficient to lengthen circadian period in BL vs. DD (24.47 v $23.95 \mathrm{~h}$, respectively, $\mathrm{p}=0.0017$ ) indicating it supports circadian light-responsiveness. A 2way ANOVA revealed a significant interaction between the pre/ exposure and MF/sham treatment $\left(F_{1,198}=5.1 p=0.025\right.$, Fig.1Di). Expression of this variant also shortened the freerunning circadian period when exposed to a MF $(300 \mu \mathrm{T}, 3 \mathrm{~Hz})$ compared to their pre-exposure and to the sham exposed flies $(p=0.023, p=0.015$, respectively, Fisher LSD test, whilst the stringent Newman-Keuls test narrowly missed significance for both comparisons $(p=0.063$, $\mathrm{p}=0.074$, Extended Data Fig.2E-F). 
Ai

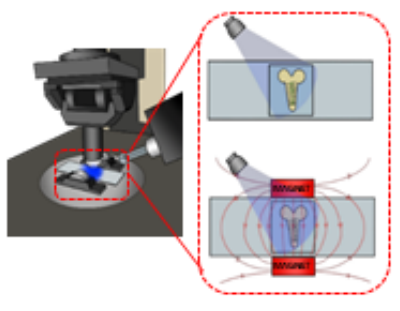

Aii elav-GAL4 > UAS-DmCry; $c r y^{02} /$ cry $^{03}$

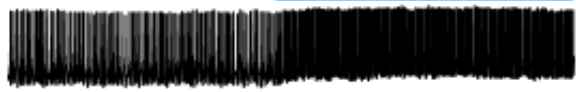

Aiii elav-GAL4 > UAS-DmCry; $c r y^{02} / \mathrm{Cry}^{03}$

B elav-GAL4> UAS-DmCry; cry $^{02} / \mathrm{Cry}^{03}$

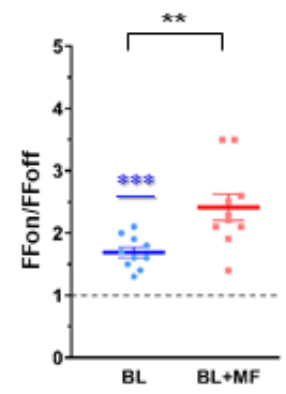

Ci tim-GAL4 > UAS-Luc-CT; Cii elav-GAIL4>UAS-Luc-
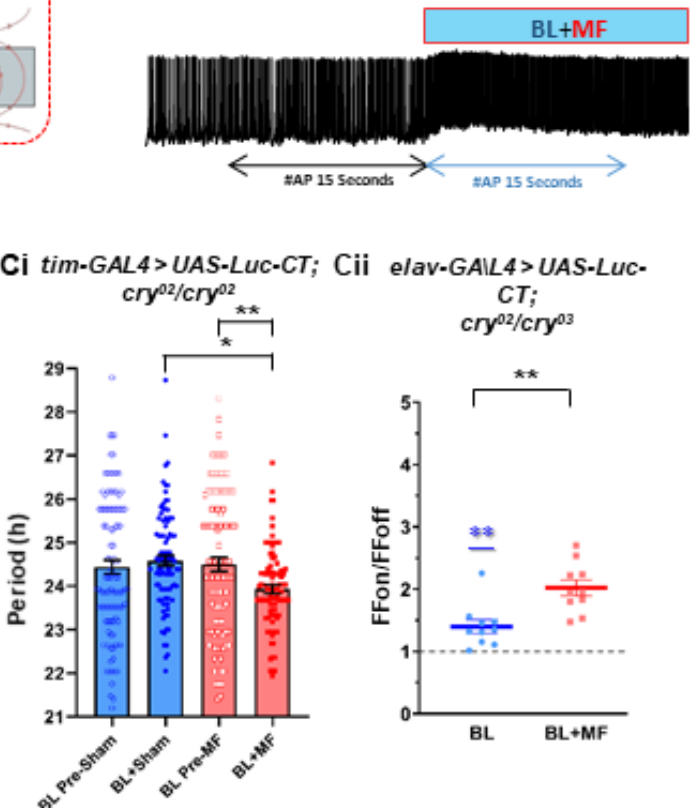

cry $^{02} /$ cry $^{03}$

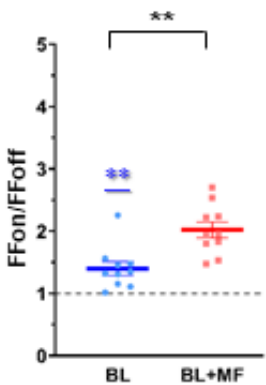

Di tim-GAL4>UAS-LUC-CT $T_{\text {W3361F; }}$ cry $^{02} /$ cry $^{02}$



Dii elav-GAL4>UAS-LUC-CT $T_{\text {W336j: }}$

cry $^{02} /$ cry $^{03}$

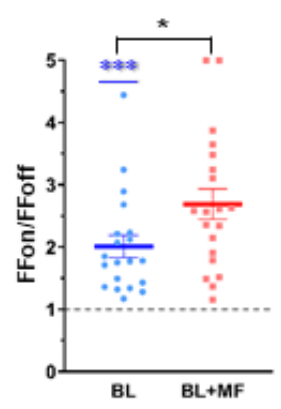

Figure 1. Luc-CT is sufficient to support magnetosensitivity.

(Ai). Electrophysiological setup in presence/absence of $100 \mathrm{mT}$ MF (Aii) BL-exposure of aCC neurons expressing DmCry increase firing. (Aiii) Co-presence of MF (100 mT) potentiates BL effect. Traces represent aCC from different preparations. (B). Relative firing frequency of aCC expressing DmCry. BL increases firing 1.69-fold $\left(t_{(9)}=7.72, p=<0.0001, n=10\right.$, Firing-Frequency on/Firing-Frequency $\left.y_{\text {off }}\right)$. External $\mathrm{MF}\left(\mathrm{BL}+\mathrm{MF}, 100 \mathrm{mT}\right.$ ) potentiates effect to 2.41-fold (BL vs $\mathrm{BL}+\mathrm{MF}, \mathrm{t}_{(18)}=3.2, \mathrm{p}=0.005, \mathrm{n}=10$, Extended Data Fig.1A). (Ci). tim-GAL4>UAS-LUC-CT; $c r y^{02} / c r y{ }^{02}$ show period shortening under MF (3-way ANOVA gives significant Sham/MF $x$ pre/post-exposure interaction $\left(F_{1,377}=7.6, p=0.006\right)$ with MF-exposed flies showing significantly shorter period than sham exposed. Each of 4 replicates (Replicates, third factor in ANOVA) showed the same period shortening under MF (Extended data Fig.2A-C). (Cii). Luc-CT supports increased aCC firing in $B L\left(1.4\right.$-fold, $t_{(9)}=4.01, p=0.003 n=10$, Extended Data Fig.1B) and 2-fold in $\mathrm{BL}+\mathrm{MF}$ ( $\mathrm{BL}$ vs $\mathrm{BL}+\mathrm{MF}, \mathrm{p}=0.002, \mathrm{t}_{(\mathrm{df}, 18)}=3.71, \mathrm{n}=10$ ). ( $\left.\mathrm{Di}\right)$. Luc- $\mathrm{CT}_{\mathrm{W}(536) \mathrm{F}}$ revealed significant period 
bioRxiv preprint doi: https://doi.org/10.1101/2021.10.29.466426; this version posted November 1, 2021. The copyright holder for this preprint (which was not certified by peer review) is the author/funder, who has granted bioRxiv a license to display the preprint in perpetuity. It is made available under aCC-BY 4.0 International license.

CRY-independent magnetosensitivity

shortening under exposure to MF (2-way ANOVA revealed significant pre/post-exposure $\mathrm{XMF} / \mathrm{sham}$ interaction $\mathrm{F}_{1,198}=5.1 \mathrm{p}=0.025$, post-hoc tests in Extended Data Fig.2E-F). (Dii). aCC expressing Luc$C T_{W(536) F}$ exhibit 2-fold change in response to $B L\left(t_{(19)}=6.06, p=<0.0001, n=20\right)$. Response to $B L+M F$ is more variable but significantly greater than BL alone (2.69-fold, 2-way ANOVA, Replicates as factor, $p=0.03, F_{(1,16)}=5.09$, Extended Data Fig.1C). Raw data used to derive electrophysiological foldchange/BL responses are shown in Extended Data Fig.1. Controls are reported in Extended Data Fig.3. For FFon/FFoff data, blue asterisks represent significance for aCC comparing before vs. after BL exposure (same cells, paired t-test); black asterisks represent comparisons of $B L v s$. BL+MF (different cells, unpaired t-test). ${ }^{*} p=\leq 0.05, * * p=\leq 0.01, * * * p=\leq 0.001$.

Expression of Luc-CT $\mathrm{W}_{(536) \mathrm{F}}$ also supported a strong (2-fold) BL response on AP firing in aCC and, again a significant, albeit more variable potentiation in BL+MF (Fig.1Dii, 2.69-fold, $p=0.03$, 2-way ANOVA replicates as a factor, Extended Data Fig.1C). We conclude that Luc$\mathrm{CT}_{\mathrm{W}(536) \mathrm{F}}$ reproduces the activity of Luc-CT at the level of both single neuron and whole organism even though the effects appear less robust.

That Luc-CT $T_{\mathrm{W}(536) \mathrm{F}}$ does not obliterate a MF response argues against a significant role for a hypothetical RP between W536 and FAD. Indeed, the weaker MF-response may be structural in origi ${ }^{32}$. Evidence suggests that an arginine (R532) in close proximity could form a cation$\pi$ interaction with W536 to stabilise an alpha helical conformation ${ }^{33}$ that would be affected by the W536F substitution. Thus, the structure of the CTT seems important to ensure a robust MF response even when it is likely that the RP is not (even in part) carried by the same molecule. Control genotypes for all experiments described above showed no response to either BL or BL+MF (Extended Data Fig.3).

\section{Free FAD supports magnetoreception.}

The fact that Luc-CT $T_{\mathrm{w}(536) \mathrm{F}}$ is sufficient to support magnetosensitivity implies that a different, non-CRY, RP is involved. In this regard, it is notable that free FAD is capable of generating a magnetically sensitive RP via intramolecular electron transfer ${ }^{7,34}$. To explore this, we supplemented additional FAD to aCC via the internal patch saline. Increasing the concentration of FAD (10 to $50 \mu \mathrm{M}$, in the patch pipette) potentiates the efficacy of Luc-CT to mediate BL-dependent increases in AP firing (Fig.2A, $R^{2}=0.71, p=0.034$ ), an effect that is enhanced in the presence of BL+MF (100 mT, p=0.015). Significantly, MF potentiation is by a fixed proportion relative to $B L$ at each FAD concentration tested (evidenced by equal gradients of lines of best fit). This is a prediction of the RPM, reflected by these data, in that providing biological saturation is not limiting, the magnetically-induced change should remain constant ${ }^{35}$. In the absence of the Luc-CT construct, FAD (up to $50 \mu \mathrm{M}$ ) induced a weak, but significant, $\mathrm{BL}$ response ( $p=0.03$, Fig.2B, Extended Data Fig.4A); however, no potentiating effect was observed in BL+MF. 




B cry $^{02} / \mathrm{cry}^{03}$ $50 \mu$ M FAD

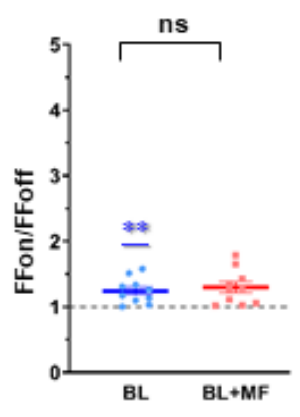

C elav-GAL4>UAS-LUC-CT; $\mathrm{cry}^{02} / \mathrm{cry}^{03}$

$50 \mu \mathrm{M}$ Riboflavin

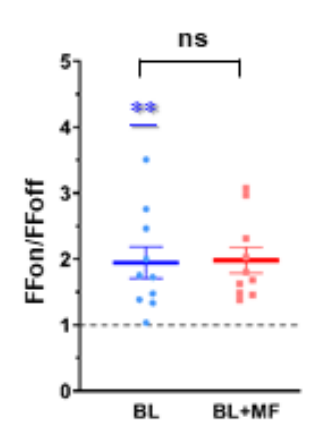

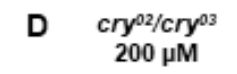

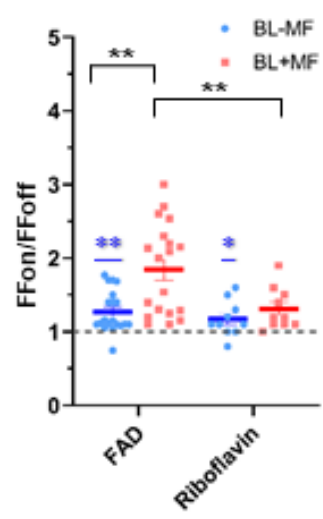

Figure 2. Free FAD potentiates the effect of Luc-CT and at high concentration supports magnetosensitivity alone.

(A). Increasing FAD in aCC (via the recording pipette) expressing Luc-CT increases the response to $B L$, demonstrated by linear regression analysis $\left(R^{2}=0.71, F_{(1,4)}=10.1, p=0.03\right)$. The co-presence of a MF $(100 \mathrm{mT})$ further increases the response $\left(F_{(1,9)}=9.06, p=0.015\right)$ by a consistent amount across concentrations tested. $n=5$ for all points except $B L 30 \mu M$ and $50 \mu M$ [FAD] for which $n=6$. (B). Addition of FAD $(50 \mu \mathrm{M})$ supports BL sensitivity (see also Extended Data Fig.4A), but not magnetosensitivity in the absence of Luc-CT and in a CRY null $\left(p=0.609, \mathrm{t}_{(18)}=0.521, \mathrm{n}=10\right)$. (C). Addition of riboflavin $(50 \mu \mathrm{M})$, supports the response to $B L$ in aCC expressing Luc-CT, but not MF potentiation $\left(t_{(18)}=0.12, p=0.91\right.$, $n=10)$. (D). Increased FAD (200 $\mu M)$, in cry ${ }^{0}$, supports $B L$-induced change in firing (1.27-fold, $t_{(19)}=4.29$, $p=0.0004, n=20$, Extended Data Fig.4C). In the co-presence of a MF ( $n=19)$, the FAD effect on $B L$ is significantly potentiated (1.84-fold, 2-way ANOVA $\left(F_{(1,55)}=3.51, p=0.066\right)$, Newman-Keuls post-hoc $\mathrm{p}=0.003)$. Riboflavin $(200 \mu \mathrm{M})$ shows a similar BL effect $\left(1.17\right.$-fold, $t_{(9)}=2.33, p=0.045$, Extended Data Fig.4C) but no MF potentiation (1.31-fold, Newman-Keuls post-hoc $\mathrm{p}=0.67$ ). Raw data can be found in Extended Data Fig.4. Blue asterisks represent significance values for aCC before vs. after BL exposure (paired t-test, same cells); black asterisks (or ns = not significant) represent comparisons of BL vs $\mathrm{BL}+\mathrm{MF}$ (unpaired t-test, different cells). ns $\mathrm{p}=>0.05, * \mathrm{p}=\leq 0.05, * * \mathrm{p}=\leq 0.01, * * * p=\leq 0.001$.

FAD autoreduction occurs following electron transfer from the adenine side chain to the photoexcited isoalloxazine, generating an intramolecular $\mathrm{RP}^{7,36}$. Although riboflavin contains the same isoalloxazine chromophore and can populate photoexcited triplet states $^{37}$, it lacks 
bioRxiv preprint doi: https://doi.org/10.1101/2021.10.29.466426; this version posted November 1, 2021. The copyright holder for this preprint (which was not certified by peer review) is the author/funder, who has granted bioRxiv a license to display the preprint in perpetuity. It is made available under aCC-BY 4.0 International license.

CRY-independent magnetosensitivity

an adenine diphosphate side chain (Extended Data Fig.5) and is thus unable to generate the same intramolecular $\mathrm{RP}^{38}$. Riboflavin $(50 \mu \mathrm{M})$, in the presence of Luc-CT, supported a $\mathrm{BL}$ effect ( 1.94-fold, Fig.2C, Extended Data Fig 4B), but there was no additional increase under $\mathrm{BL}+\mathrm{MF}(100 \mathrm{mT}$, Fig.2C, $\mathrm{p}=0.9)$.

Our results are consistent with an interaction between FAD and Luc-CT, possibly in complex with other, unknown, molecules, which together may facilitate transduction of a magnetic signal. Furthermore, our data suggest that molecules other than CRY are able to generate magnetically-sensitive RPs and produce a biological effect under appropriate conditions. In vitro spectroscopy has shown that BL photoexcited FAD generates RPs that are responsive to MFs, ${ }^{39}$ and it appears likely that FAD is responsible for MF effects recently observed on cellular autofluorescence ${ }^{34}$. Thus, FAD (but not riboflavin) at higher concentrations may act as a magnetoreceptor. To test this, we recorded from aCC in a crynull background, which shows no overall BL or MF response (Extended Data Fig.3). We observed that high levels of FAD in the internal patch saline $(200 \mu \mathrm{M})$ was sufficient to support a BL-dependent increase in AP firing without need for Luc-CT (Fig.2D, 1.27-fold, Extended Data Fig.4C). Remarkably, this effect was potentiated, in the presence of a MF (100 mT, Fig.2D, 1.84-fold, $p=0.003)$. Cells supplemented with riboflavin $(200 \mu \mathrm{M})$ showed an increase in APs in response to BL (Fig.2D, Extended Data Fig.4C) but did not show potentiation of the response in a MF (100 mT, $\mathrm{p}=0.67)$.

\section{The integrity of the CTT is crucial for magnetic sensitivity.}

Activity of Luc-CT $\mathrm{W}_{\text {(536)F }}$ (Fig.1D) highlights that the integrity of the CTT appears to be important to its role in facilitating magnetosensitivity. The CTT of CRY also contains several linear motifs including putative PDZ-binding sequences ${ }^{40}$ (e.g., EEEV 528-531, Fig.3A). PDZ proteins function as modular scaffolds that direct the cellular localisation of signalling molecules such as ion channels (for instance, Shaker $\left.\mathrm{K}^{+}\right)^{41,42}$ and assembly of signalling partners (including CRY) into a 'signalplex' of the photo-transduction cascade in the Drosophila eye ${ }^{20,21}$. To explore the importance of CTT structure and, specifically, to determine whether the putative PDZ-binding motif at residues 528-531 regulates magnetosensitivity, we mutated valine to lysine in position 531 (V531K) ${ }^{40}$ in full-length DmCry. Pan-circadian expression (i.e., using the tim-GAL4 driver) of $\mathrm{DmCry}_{\mathrm{v}(531) \mathrm{K}}$ in a $c r y^{02}$ background retained a circadian light sensitivity with a slight period shortening (Fig.3B, DD=24.51 vs $B L=24.20 \mathrm{~h}, \mathrm{p}=0.005$, Grubbs outlier test excluded a single very weakly rhythmic short period (20.3 h) fly in DD, see Methods), but failed to support a whole-organism behavioural response to MF (Fig.3B, $F_{1,55}=0.932, p=0.76$, Extended Data Fig.6A). Expression of $\operatorname{DmCry}_{(531) \mathrm{K}}$ in aCC showed the expected effect of $\mathrm{BL}$ 
bioRxiv preprint doi: https://doi.org/10.1101/2021.10 29.466426; this version posted November 1, 2021. The copyright holder for this preprint (which was not certified by peer review) is the author/funder, who has granted bioRxiv a license to display the preprint in perpetuity. It is made available under aCC-BY 4.0 International license.

CRY-independent magnetosensitivity

on AP firing (Fig.3C, 1.76-fold, Extended Data Fig.6B). However, as in the circadian assay, this variant was unable to support magnetosensitivity ( $100 \mathrm{mT}$, Fig.3C, $\mathrm{p}=0.77$ ). The loss of a MF effect, but retention of a $\mathrm{BL}$ response for $\operatorname{DmCry}_{\mathrm{v}(531) \mathrm{K}}$ is reminiscent of the $\mathrm{CRY} \Delta$ mutant $^{3,4}$, which lacks the CTT entirely. These results confirm the CTT as a probable mediator of the MF response, where it likely serves to facilitate formation of protein complexes that transduce a magnetic signal.

A


C elav-GAL4 > UAS-DmCry $\mathrm{V}_{1531, k}$ $\mathrm{cry}^{02} / \mathrm{cry}^{03}$



Figure 3. Integrity of the CTT is required for magnetosensitivity.

(A). Cartoon of the domain structure of CRY including the CT (aa 491-542) and CTT (aa 521-542). The four Trp residues, essential for the canonical RPM, are indicated by red asterisks. A putative PDZ

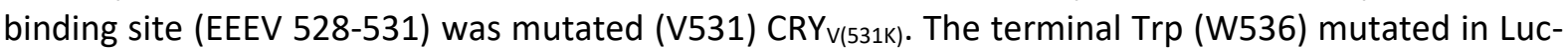
$\mathrm{CT}_{\text {(W536F })}$ is shown in green. (B). $\mathrm{CRY}_{\mathrm{V}(531) \mathrm{K}}$ expressed in clock neurons (tim-Gal4) does not support magnetosensitivity in the circadian assay. 2-way ANOVA revealed no significant main, or interaction effects (interaction, $F_{1,52}=0.09, p=0.77$, Extended Data Fig6.A). (C). Expression of $C^{2} Y_{v(531) k}$ in aCC neurons is sufficient to support a response to $B L\left(p=0.017, t_{(9)}=2.934, n=10\right)$ but not a potentiation in $\mathrm{BL}+\mathrm{MF}\left(100 \mathrm{mT}, \mathrm{p}=0.768, \mathrm{t}_{(18)}=0.299, \mathrm{n}=10\right)$. Raw data are shown in Extended Data Fig.6. Blue asterisks represent significance values for aCC before vs. after BL exposure (paired t-test, same cells); ns (not significant) represent comparisons of $B L$ vs $B L+M F$ (unpaired t-test, different cells). ns $p=>0.05, *$ $\mathrm{p}=\leq 0.05, * * \mathrm{p}=\leq 0.01, * * * \mathrm{p}=\leq 0.001$.

\section{Conclusions.}

We have observed that contrary to several reports 2,13 , but not others ${ }^{3}$, full length CRY may be sufficient, but is not strictly necessary, to mediate Drosophila magnetosensitivity. The 
bioRxiv preprint doi: https:/doi.org/10.1101/2021.10.29.466426; this version posted November 1, 2021. The copyright holder for this preprint (which was not certified by peer review) is the author/funder, who has granted bioRxiv a license to display the preprint in perpetuity. It is made available under aCC-BY 4.0 International license.

CRY-independent magnetosensitivity

expression of the C-terminal 52 residues of CRY is sufficient to support magnetosensitivity in both single neuron and whole animal assays. Despite being different measures, it is notable that a $300 \mu \mathrm{T}$ MF results in a decrease in circadian period whereas a $100 \mathrm{mT}$ MF results in an increase in AP firing. The RPM mechanism predicts biphasic responses to $\mu \mathrm{T}$ MF and $\mathrm{mT} M F$ that are opposite in this way ${ }^{35}$. Thus, whilst our data challenge the canonical CRY-dependent RPM model of animal magnetoreception, they are nonetheless consistent with a RPM. Although animals are not likely to sense a $100 \mathrm{mT}$ MF in nature, in the context of MF effects on RP reactions, mechanistic insight such as this is only possible when working in both $\mu \mathrm{T} M F$ and $\mathrm{mT}$ MF regimes.

Luc-CT neither binds the FAD cofactor directly nor does it contain the chain of Trp residues considered essential for the canonical CRY-based RPM. However, the Luc-CT response is potentiated by increasing the cytosolic availability of FAD, a common biological redox cofactor, confirming that redox reactions are at the core of magnetosensitivity ${ }^{43}$. The finding that alternative RPs can transduce physiological MF effects also suggests that other, nonphotochemical RPs, may contribute to magnetoreception, which is consistent with a growing list of examples reporting RP mediated magnetoreception in darkness ${ }^{29,44-46}$. The synergistic interaction between LuC-CT and free FAD suggests the former facilitates formation of a complex that enables the transduction of a magnetic signal by the latter. However, given that free FAD itself can mediate a magnetic response in vivo, we suggest that CRY has evolved to bring the RP and effectors in close proximity in order to potentiate the comparatively weak activity of the geoMF. In this regard CRY may not be the primary magnetoreceptor. This view is in contrast to a recent in vitro spectroscopic study that suggested that full length CRY itself is the magnetoreceptor ${ }^{47}$. By contrast, our observations suggest an ancient and ubiquitous effect of MFs on biological RPs that evolution has optimised, through CRY and partners, to function as a magnetoreceptor.

This paper is supported by an extended data file 
bioRxiv preprint doi: https://doi.org/10.1101/2021.10 29.466426; this version posted November 1, 2021. The copyright holder for this preprint (which was not certified by peer review) is the author/funder, who has granted bioRxiv a license to display the preprint in perpetuity. It is made available under aCC-BY 4.0 International license.

CRY-independent magnetosensitivity

\section{Materials and Methods:}

\section{Fly stocks}

For larval recordings, embryos were raised at $25^{\circ} \mathrm{C}$ in a $12: 12$ light / dark cycle until $3^{\text {rd }}$ instar wall climbing larvae (L3) emerged, these were then kept in darkness through the day of recording to minimise light dependent $\mathrm{CRY}$ degradation. Recordings were conducted between circadian time hours: $2-10$. Flies were maintained on standard corn meal medium at $25^{\circ} \mathrm{C}$. The driver line elav ${ }^{C 155}$-GAL4; ; cry ${ }^{03}$ was obtained from Bloomington Stock centre (\#BL458) and crossed into a $c r y^{0}$ background as described ${ }^{48}$. $c r y^{0}$ flies were obtained from Bloomington Stock centre (\#BL86267). UAS-cry; cry ${ }^{02}$ is already described ${ }^{3,49}$.

\section{Molecular Cloning of Luc-CT}

Luciferase CDS was cloned from the UAS-Luc-CRY fly line ${ }^{17}$ and subsequently amplified with the following primers to include overhangs compatible for the NEB Gibson Assembly assay

F: TATCCTTTACTTCAGGCGGCCGCATGGAAGACGCCAAAAACATAAAGAAAGG;

R: TCCGGATACTCGAGCACGGCGATCTTTCCGCCC.

The CT portion of cry was produced by gene synthesis (GeneArt, ThermoScientific) based on the original GFP-CT construct ${ }^{3}$. CT was designed to include 5' and 3' overhangs compatible with subsequent NEB Gibson Assembly assay (Seq:AAAGATCGCCGTGCTCGAGTATCCGGAGCGGATCATTGATTTGTCCATGGCCGTG AAGCGCAACATGCTGGCCATGAAGTCCCTGCGCAACAGCCTGATCACCCCCCCACCAC ATTGCCGCCCCAGCAATGAGGAGGAAGTGCGCCAGTTCTTCTGGCTGGCCGATGTGGT GGTGTAATCTAGAGGATCTTTGTGAAGGA).

pJFRC2-10XUAS-IVS-mCD8::GFP (Addgene \#26214) plasmid was digested with Notl and Xbal. A Gibson Assembly assay was performed to ligate pJFRC, LUC and CT in a single step reaction. A Myc tag was produced by annealing single Oligos designed using The Oligator software (11avidson.edu) and ligated 5' of Luc-CT. Briefly, $5 \mu \mathrm{M}$ of Oligos

47-mer Top1

5'-GATCTCACAATGGAACAGAAGCTGATCTCCGAGGAGGACCTGGGCGC

47-mer Bottom1

\section{5’ GGCCGCGCCCAGGTCCTCCTCGGAGATCAGCTTCTGTTCCATTGTGA}

Resulting in 5' BgIll and 3' Notl over-hangs once annealed, were diluted in 1X annealing buffer (0.1 M NaCl; $10 \mathrm{mM}$ Tris-HCl, $\mathrm{pH}$ 7.4), boiled in $500 \mu$ l of $\mathrm{H}_{2} \mathrm{O}$ for 10 minutes and left overnight to cool down to room temperature to hybridise. The pJFRC2-10XUAS-Luc-CT plasmid was then digested with BgIII and Notl. The fragment encoding the Myc tag was then ligated using 
bioRxiv preprint doi: https:/doi.org/10.1101/2021.10.29.466426; this version posted November 1, 2021. The copyright holder for this preprint (which was not certified by peer review) is the author/funder, who has granted bioRxiv a license to display the preprint in perpetuity. It is made available under aCC-BY 4.0 International license.

CRY-independent magnetosensitivity

standard methods. After sequence validation, the plasmid was injected into the $y w, M(e G F P$, vas-int, dmRFP)ZH-2A; $P\{$ CaryP\}attP40 (Stock 13-40, Cambridge University Fly facility) using the Phi31 integrase system for insertion. The resulting transformants were subsequently backcrossed into the $w^{1118}$ background for 7 generations.

The Luc-CT ${ }_{\mathrm{W}(536) \mathrm{F}}$ transgene was generated by gene synthesis (Eurofins, Ebersberg, Germany) and sub-cloned into pJFRC-MUH via 5' Notl and 3' Xbal restriction sites. Transgenic injections for Luc-CTw(536)F were carried out by Manchester University Fly Facility using the same $y w$ M(eGFP, vas-int, dmRFP)ZH-2A; P\{CaryP\}attP40 line (Stock 13-40, University of Cambridge Fly Facility).

$H_{A-{ }^{-}} y_{(V 531 K)}$ (containing a HA tag at the $\mathrm{N}$-terminal of the encoded protein) was already available as a clone into the yeast plasmid pEG202 ${ }^{40}$. It was released by EcoRI-Xhol digestion and subcloned into pUAST ${ }^{50}$. Transgenics were produced by P-element transformation by the University of Cambridge Fly Facility using the line S(6)1 inserted on chromosome 2.

\section{Electrophysiology}

The experimenter was blinded to genotype during both recordings and subsequent data analysis. L3 larvae were dissected under extracellular saline as described ${ }^{51}$ with the only modification being a red filter applied to both the dissecting light and compound microscope to minimise $\mathrm{CRY}$ degradation prior to, and during, recordings. Thick-walled borosilicate glass electrodes (GC100F-10; Harvard Apparatus, UK) were fire polished to resistances of $10-15$ $M \Omega$. Recordings were made using a Multiclamp 700B amplifier controlled by $\mathrm{PCLAMP}$ (version 10.4) via a Digidata 1440A analog-to-digital converter (Molecular Devices, CA, USA) and only cells with an input resistance of $\geq 500 \mathrm{M} \Omega$ were used. Traces were filtered at $10 \mathrm{kHz}$ and sampled at $20 \mathrm{kHz}$. The extracellular saline solution contained the following (in $\mathrm{mM}$ ): $135 \mathrm{NaCl}$, $5 \mathrm{KCl}, 4 \mathrm{MgCl}_{2} .6 \mathrm{H}_{2} \mathrm{O}, 2 \mathrm{CaCl}_{2} .2 \mathrm{H}_{2} \mathrm{O}, 5 \mathrm{TES}$, and 36 sucrose, $\mathrm{pH}$ 7.15. The intracellular patch solution contained the following (in $\mathrm{mM}$ ): $140 \mathrm{~K}$-D-gluconate, $2 \mathrm{MgCl}_{2} \cdot 6 \mathrm{H}_{2} \mathrm{O}, 2 \mathrm{EGTA}, 5 \mathrm{KCl}$, and 20 HEPES, $\mathrm{pH}$ 7.4. $\mathrm{KCl}$ and $\mathrm{CaCl}_{2}$ were from Fisher Scientific (UK); sucrose was from $\mathrm{BDH}(\mathrm{UK})$; all remaining chemicals were from Sigma-Aldrich (UK). Mecamylamine (1 mM) was applied to all preparations to isolate the aCC motoneurons from excitatory cholinergic synaptic input. For recordings supplemented with additional FAD or riboflavin (Sigma-Aldrich, UK) dilutions were made up in intracellular saline and kept in the dark. 
bioRxiv preprint doi: https://doi.org/10.1101/2021.10.29.466426; this version posted November 1, 2021. The copyright holder for this preprint (which was not certified by peer review) is the author/funder, who has granted bioRxiv a license to display the preprint in perpetuity. It is made available under aCC-BY 4.0 International license.

CRY-independent magnetosensitivity

\section{Photoactivation and Magnetic Field application}

Light stimulation was supplied by a blue LED (470 nm, Cairn Research, UK) at a power of $\sim 2.2 \mathrm{~mW} / \mathrm{cm}^{2}$, a value used previously to stimulate $C R Y^{52}$. Each cell was injected with a variable amount of constant current until threshold potential was reached and the neuron was allowed to settle until AP firing was $\sim 5-7 \mathrm{~Hz}$. Once a stable firing rate was achieved, each neuron was recorded for at least $20 \mathrm{~s}$ before exposure to $\mathrm{BL}$ illumination for $30 \mathrm{~s}$. Magnetic exposure was provided by two $\mathrm{NeFeB}$ static magnets mounted around the preparation at a distance that provided a MF of $100( \pm 5) \mathrm{mT}$. Field strength was measured using a 5180 Gauss/Tesla Meter (F.W. Bell. USA). This method is essentially identical to that used previously 4 .

\section{Statistical analysis of electrophysiological recordings}

A D’Agostino \& Pearson analysis showed our data to be normally distributed, thus parametric tests were applied in all cases. Data are shown as mean \pm SEM. To determine BL sensitivity a paired t-test (two-tailed) was used to compare the number of APs a neuron fired in the $15 \mathrm{~s}$ following light stimulation to the number of APs in the preceding $15 \mathrm{~s}$ before light exposure. For comparison between $\mathrm{BL}$ and $\mathrm{BL}+\mathrm{MF}$ the number of $\mathrm{APs}$ in the $15 \mathrm{~s}$ preceding and proceeding $\mathrm{BL}$ or $\mathrm{BL}+\mathrm{MF}$ exposure was used to determine the firing-fold change $\left(\mathrm{FF}_{\mathrm{on}} / \mathrm{FF}_{\text {off }}\right)$ for each cell. Statistical significance for MF potentiation against BL effect alone was determined using an unpaired t-test (two-tailed) to compare the firing-fold change for the $\mathrm{BL}$ population to the $\mathrm{BL}+\mathrm{MF}$ population. Where multiple genotypes/conditions were tested simultaneously, a 2-way ANOVA with Newman-Keuls post-hoc testing was used. For the FAD dose response curve, a $\mathrm{BL}$ effect of [FAD] was determined by linear regression fitting and significance determined using an ANCOVA model. Average MF potentiation of the Luc-CT FAD dose response (Fig.2A) was determined based on the intercept of the $Y$ axis. Unpaired t-tests (two-tailed) were also applied in the Extended Data figures to compare the number of APs in the 'before' $B L \pm M F$ conditions, as well as to $B L$ and $B L+M F$ exposures. Control lines were also compared to their respective experimental genotype by both 1-way ANOVA (with $\mathrm{BL}$ and $\mathrm{BL}+\mathrm{MF}$ recordings separated) and by 2-way ANOVA. Raw data are reported in the Extended Data.

\section{Behavioural analyses and statistics}

Circadian locomotor activity was recorded using a Drosophila Trikinetics Monitor 2 (Waltham, MA, USA) ${ }^{3}$. To test the effects of MF on the free-running circadian period of locomotor activity, we used a modified version of the Schuderer apparatus, which consists of two independent 
bioRxiv preprint doi: https:/doi.org/10.1101/2021.10.29.466426: this version posted November 1, 2021. The copyright holder for this preprint (which was not certified by peer review) is the author/funder, who has granted bioRxiv a license to display the preprint in perpetuity. It is made available under aCC-BY 4.0 International license.

CRY-independent magnetosensitivity

double wrapped coils placed inside two $\mu$-metal boxes within a commercial incubator. The shielded, four quadratic Helmholtz coil systems produce a homogenous, linearly polarized $B$ field with perpendicular orientation to the horizontal plane of the Trikinetics monitors. Each coil is formed with a pair of wires, with the current passing in the same direction through both wires for MF exposure but in opposite directions to provide a sham exposure condition. A computer randomly assigns the MF and Sham exposed chambers and the experiment is performed blind from the experimenter ${ }^{17}$.

One to three day old flies were first entrained at $20^{\circ} \mathrm{C}$ in the apparatus under a dim $\mathrm{BL}$ : darkness $12 \mathrm{~h}$ cycle $(\mathrm{BL}: \mathrm{DD}=12: 12$ ) for three full days, before being pre-exposed to continuous $B L$ for 7 days, followed by exposure to $B L+M F$ or $B L+S h a m$ for a further 7 days ${ }^{3}$. Thus, there were 4 measurements, the pre-exposure $(B L)$ period of flies that were subjected to a MF or sham, plus the exposure period for both (BL+MF and BL+Sham). A fifth control condition examined the period of Luc-CT; $c r y^{02}$ in DD without exposure. All experiments were performed using a low frequency $3 \mathrm{~Hz}$ field at $300 \mu \mathrm{T}$ and $\operatorname{dim} \mathrm{BL}$ at $0.15-0.25 \mu \mathrm{W} / \mathrm{cm}^{2}$, wavelength $450 \mathrm{~nm}, 40 \mathrm{~nm}$ broad range (RS Components, UK).

Rhythmicity and period were determined using spectral analysis employing a MatLab-based version of the BeFly program ${ }^{53}$. Statistical analysis of period was performed using ANOVA with either Statistica (Statsoft, CA, USA) for factorial analyses or Prism (Graphpad) for 1-way ANOVA. Although there was a clear prediction that Luc-CT flies would have a shorter period under a $\mathrm{MF}^{3}$ we nevertheless used the stringent Newman-Keuls post-hoc test to compare groups after factorial ANOVA buttressed by the more liberal Fisher LSD test for the circadian Luc- $C T_{\mathrm{W}(536) \mathrm{F}}$ results. To compare the DD periods with those from the $\mathrm{BL}$ pre-exposure conditions we used an unpaired t-test. Circadian data were first tested using a Grubbs outlier test (GraphPad Prism, alpha $=0.01$ two-sided, $Z=5.3$ ). One datum from the DD data of $\mathrm{CRY}_{\mathrm{V}(531) \mathrm{K}}$ which represented the least robust single period in the dataset with an anomalous period of $20.3 \mathrm{~h}$ (8 sd away from the mean) was identified and removed. 
bioRxiv preprint doi: https://doi.org/10.1101/2021.10.29.466426; this version posted November 1,2021 . The copyright holder for this preprint (which was not certified by peer review) is the author/funder, who has granted bioRxiv a license to display the preprint in perpetuity. It is made available under aCC-BY 4.0 International license.

CRY-independent magnetosensitivity

\section{References:}

1. Wiltschko, W. \& Wiltschko, R. Magnetic orientation and magnetoreception in birds and other animals. Journal of Comparative Physiology A: Neuroethology, Sensory, Neural, and Behavioral Physiology vol. 191 675-693 (2005).

2. Hore, P. J. \& Mouritsen, H. The Radical-Pair Mechanism of Magnetoreception. Annu. Rev. Biophys. 45, 299-344 (2016).

3. Fedele, G. et al. Genetic Analysis of Circadian Responses to Low Frequency Electromagnetic Fields in Drosophila melanogaster. PLoS Genet. 10, (2014).

4. Giachello, C. N. G., Scrutton, N. S., Jones, A. R. \& Baines, R. A. Magnetic fields modulate blue-light-dependent regulation of neuronal firing by cryptochrome. $J$. Neurosci. 36, 10742-10749 (2016).

5. Schwarze, S. et al. Weak broadband electromagnetic fields are more disruptive to magnetic compass orientation in a night-migratory songbird (Erithacus rubecula) than strong narrow-band fields. Front. Behav. Neurosci. 10, 1-13 (2016).

6. Günther, A. et al. Double-Cone Localization and Seasonal Expression Pattern Suggest a Role in Magnetoreception for European Robin Cryptochrome 4. Curr. Biol. 28, 211223.e4 (2018).

7. Antill, L. M. \& Woodward, J. R. Flavin Adenine Dinucleotide Photochemistry Is Magnetic Field Sensitive at Physiological pH. J. Phys. Chem. Lett. 9, 2691-2696 (2018).

8. Wan, G., Hayden, A. N., liams, S. E. \& Merlin, C. Cryptochrome 1 mediates lightdependent inclination magnetosensing in monarch butterflies. Nat. Commun. 12, 1-9 (2021).

9. Ritz, T., Adem, S. \& Schulten, K. A model for photoreceptor-based magnetoreception in birds. Biophys. J. 78, 707-718 (2000).

10. Ritz, T. et al. Magnetic compass of birds is based on a molecule with optimal directional sensitivity. Biophys. J. 96, 3451-3457 (2009).

11. Kao, Y. T. et al. Ultrafast dynamics and anionic active states of the flavin cofactor in cryptochrome and photolyase. J. Am. Chem. Soc. 130, 7695-7701 (2008).

12. Immeln, D., Weigel, A., Kottke, T. \& Pérez Lustres, J. L. Primary events in the blue light sensor plant cryptochrome: Intraprotein electron and proton transfer revealed by femtosecond spectroscopy. J. Am. Chem. Soc. 134, 12536-12546 (2012).

13. Rodgers, C. T. \& Hore, P. J. Chemical magnetoreception in birds: The radical pair mechanism. Proceedings of the National Academy of Sciences of the United States of America vol. 106 353-360 (2009).

14. Giovani, B., Byrdin, M., Ahmad, M. \& Brettel, K. Light-induced electron transfer in a cryptochrome blue-light photoreceptor. Nat. Struct. Biol. 10, 489-490 (2003).

15. Rosato, E. et al. Light-dependent interaction between Drosophila CRY and the clock protein PER mediated by the carboxy terminus of CRY. Curr. Biol. 11, 909-917 (2001).

16. Dissel, S. et al. A constitutively active cryptochrome in Drosophila melanogaster. Nat. Neurosci. 7, 834-840 (2004).

17. Peschel, N., Chen, K. F., Szabo, G. \& Stanewsky, R. Light-Dependent Interactions between the Drosophila Circadian Clock Factors Cryptochrome, Jetlag, and Timeless. Curr. Biol. 19, 241-247 (2009). 
bioRxiv preprint doi: https://doi.org/10.1101/2021.10.29.466426; this version posted November 1,2021 . The copyright holder for this preprint (which was not certified by peer review) is the author/funder, who has granted bioRxiv a license to display the preprint in perpetuity. It is made available under aCC-BY 4.0 International license.

CRY-independent magnetosensitivity

18. Zoltowski, B. D. et al. Structure of full-length Drosophila cryptochrome. Nature 480, 396-399 (2011).

19. Levy, C. et al. Updated structure of Drosophila cryptochrome. Nature vol. 495 396-399 (2013).

20. Ye, F. et al. An unexpected INAD PDZ tandem-mediated plc $\beta$ binding in drosophila photo receptors. Elife 7, (2018).

21. Mazzotta, G. M. et al. Calmodulin Enhances Cryptochrome Binding to INAD in Drosophila Photoreceptors. Front. Mol. Neurosci. 11, 1-15 (2018).

22. Müller, P., Brettel, K., Grama, L., Nyitrai, M. \& Lukacs, A. Photochemistry of Wild-Type and N378D Mutant E. coli DNA Photolyase with Oxidized FAD Cofactor Studied by Transient Absorption Spectroscopy. ChemPhysChem 17, 1329-1340 (2016).

23. Nohr, D. et al. Extended Electron-Transfer in Animal Cryptochromes Mediated by a Tetrad of Aromatic Amino Acids. Biophys. J. 111, 301-311 (2016).

24. Lin, C., Top, D., Manahan, C. C., Young, M. W. \& Crane, B. R. Circadian clock activity of cryptochrome relies on tryptophan-mediated photoreduction. Proc. Natl. Acad. Sci. U. S. A. 115, 3822-3827 (2018).

25. Gegear, R. J., Foley, L. E., Casselman, A. \& Reppert, S. M. Animal cryptochromes mediate magnetoreception by an unconventional photochemical mechanism. Nature 463, 804-807 (2010).

26. Baik, L. S. et al. Distinct mechanisms of Drosophila CRYPTOCHROME-mediated lightevoked membrane depolarization and in vivo clock resetting. Proc. Natl. Acad. Sci. U. S. A. 116, 23339-23344 (2019).

27. Biskup, T. et al. Variable electron transfer pathways in an amphibian cryptochrome tryptophan versus tyrosine-based radical pairs. J. Biol. Chem. 288, 9249-9260 (2013).

28. Solov'yov, I. A. \& Schulten, K. Magnetoreception through cryptochrome may involve superoxide. Biophys. J. 96, 4804-4813 (2009).

29. Wiltschko, R., Ahmad, M., Nießner, C., Gehring, D. \& Wiltschko, W. Light-dependent magnetoreception in birds: The crucial step occurs in the dark. J. R. Soc. Interface 13, (2016).

30. Foley, L. E., Gegear, R. J. \& Reppert, S. M. Human cryptochrome exhibits lightdependent magnetosensitivity. Nat. Commun. 2, 353-356 (2011).

31. Miura, T., Maeda, K. \& Arai, T. Effect of Coulomb interaction on the dynamics of the radical pair in the system of flavin mononucleotide and hen egg-white lysozyme (HEWL) studied by a magnetic field effect. J. Phys. Chem. B 107, 6474-6478 (2003).

32. Czarna, A. et al. Structures of Drosophila Cryptochrome and Mouse Cryptochrome1 Provide Insight into Circadian Function. Cell 153, 1394-1405 (2013).

33. Shi, Z., Olson, C. A. \& Kallenbach, N. R. Cation-m interaction in model $\alpha$-helical peptides. J. Am. Chem. Soc. 124, 3284-3291 (2002).

34. Ikeya, N. \& Woodward, J. R. Cellular autofluorescence is magnetic field sensitive. Proc. Natl. Acad. Sci. U. S. A. 118, (2021).

35. Steiner, U. E. \& Ulrich, T. Magnetic field effects in chemical kinetics and related phenomena. Chem. Rev. 89, 51-147 (1989).

36. Murakami, M., Maeda, K. \& Arai, T. Structure and kinetics of the intermediate biradicals 
bioRxiv preprint doi: https://doi.org/10.1101/2021.10.29.466426; this version posted November 1,2021 . The copyright holder for this preprint (which was not certified by peer review) is the author/funder, who has granted bioRxiv a license to display the preprint in perpetuity. It is made available under aCC-BY 4.0 International license.

CRY-independent magnetosensitivity

generated from intramolecular electron transfer reaction of FAD studied by an action spectrum of the magnetic field effect. Chem. Phys. Lett. 362, 123-129 (2002).

37. Henbest, K. B., Kukura, P., Rodgers, C. T., Hore, P. J. \& Timmel, C. R. Radio frequency magnetic field effects on a radical recombination reaction: A diagnostic test for the radical pair mechanism. J. Am. Chem. Soc. 126, 8102-8103 (2004).

38. Kowalczyk, R. M., Schleicher, E., Bittl, R. \& Weber, S. The photoinduced triplet of flavins and its protonation states. J. Am. Chem. Soc. 126, 11393-11399 (2004).

39. Timmel, C. R. et al. Magnetic field effects in flavoproteins and related systems. doi:10.1098/rsfs.2013.0037.

40. Hemsley, M. J. et al. Linear motifs in the C-terminus of D. melanogaster cryptochrome. Biochem. Biophys. Res. Commun. 355, 531-537 (2007).

41. Zito, K., Fetter, R. D., Goodman, C. S. \& Isacoff, E. Y. Synaptic clustering of Fasciclin II and Shaker: Essential targeting sequences and role of dig. Neuron 19, 1007-1016 (1997).

42. Thomas, U. et al. Synaptic targeting and localization of Discs-large is a stepwise process controlled by different domains of the protein. Curr. Biol. 10, 1108-1117 (2000).

43. Fogle, K. J. et al. Cryptochrome-mediated phototransduction by modulation of the potassium ion channel $\beta$-subunit redox sensor. Proc. Natl. Acad. Sci. U. S. A. 112, 2245-2250 (2015).

44. Pooam, M. et al. Magnetic sensitivity mediated by the Arabidopsis blue-light receptor cryptochrome occurs during flavin reoxidation in the dark. Planta 249, 319-332 (2019).

45. Hammad, M. et al. Cryptochrome mediated magnetic sensitivity in Arabidopsis occurs independently of light-induced electron transfer to the flavin. Photochem. Photobiol. Sci. 19, 341-352 (2020).

46. Netušil, R. et al. Cryptochrome-dependent magnetoreception in heteropteran insect continues even after 24 hours in darkness. J. Exp. Biol. (2021) doi:10.1242/JEB.243000.

47. Xu, J. et al. Magnetic sensitivity of cryptochrome 4 from a migratory songbird. Nat. 2021 5947864 594, 535-540 (2021).

48. Dolezelova, E., Dolezel, D. \& Hall, J. C. Rhythm defects caused by newly engineered null mutations in Drosophila's cryptochrome gene. Genetics 177, 329-345 (2007).

49. Gegear, R. J., Casselman, A., Waddell, S. \& Reppert, S. M. Cryptochrome mediates light-dependent magnetosensitivity in Drosophila. Nature 454, 1014-1018 (2008).

50. Brand, A. H. \& Perrimon, N. Targeted gene expression as a means of altering cell fates and generating dominant phenotypes. Development 118, 401-415 (1993).

51. Baines, R. A. \& Bate, M. Electrophysiological development of central neurons in the Drosophila embryo. J. Neurosci. 18, 4673-4683 (1998).

52. Fogle, K. J., Parson, K. G., Dahm, N. a \& Holmes, T. C. Neuronal Firing Rate. Paleobiology 09, 1409-1413 (2011).

53. Rosato, E. \& Kyriacou, C. P. Analysis of locomotor activity rhythms in Drosophila. Nat. Protoc. 1, 559-568 (2006). 